\title{
Factors affecting the healthcare-seeking behavior of mothers regarding their children in a rural community of Darjeeling district, West Bengal
}

\section{Nilanjana Ghosh, Indranil Chakrabarti', Manasi Chakraborty, Romy Biswas}

Departments of Community Medicine, and

${ }^{1}$ Pathology, North Bengal Medical College, Sushrutanagar, Darjeeling, India

Address for the Correspondence:

Dr. Indranil Chakrabarti, Department of Pathology, North Bengal Medical College, Sushrutanagar, Darjeeling, West Bengal - 734 012, India. E-mail: drinch@rediffmail.com

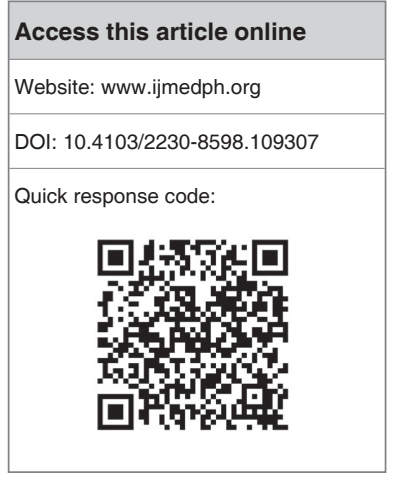

Background: An ailing, unresponsive health system and the existing social complexities, with considerable contextual differences, are all pervasive in India. In health, these are manifested as differences in morbidity and mortality, severely affecting child health and survival. Objectives: To find out the possible factors affecting the health-seeking behavior of mothers with regard to their children, in a rural community of Darjeeling district, and the reasons for not seeking curative care for perceived sick children. Materials and Methods: A cross-sectional, community-based study among the mothers of the Naxalbari Block was undertaken, using a multistage random sampling technique, from June to August 2011, by using the questionnaire method. A total of 256 mothers (sample size) were studied. Results: Joint family structure, mass media exposure, literacy status, socioeconomic status of mothers, and gender differences among children were found to be significantly associated with the healthcare-seeking behavior of the mothers. Conclusion: Increasing maternal education, intensified awareness generation through the mass media approach, implementing gender-sensitive interventions, and counseling, may have positive implications in future, leading to better health outcomes and favorable health indicators.

Key words: Gender differences, health-seeking behavior, mothers

\section{INTRODUCTION}

Diseases in children have long-term effects both in cognitive and physical infirmities. Thus, utmost care should be taken to prevent diseases, recognize the danger signals, and treat them urgently. Healthcare-seeking behavior is thus of prime importance and is pivotal in the well-being of the individual as well as the community. The process of responding to perceived 'illness' or seeking care involves multiple steps. ${ }^{[1]}$ Rahman argued that a woman's decision to seek healthcare is not an off isolated event, but a composite result of her personal needs, social forces, actions of healthcare providers, and the location of services. ${ }^{[2]}$ Thus, traditionally, while healthcare-seeking behavior is conceptualized as a 'sequence of remedial actions' taken to rectify 'perceived ill-health,' nowadays a wider perspective on affirmative, health-promoting behaviors are adopted. ${ }^{[3]}$ In patriarchal systems, dominating most of India, compounded with unemployment, illiteracy, and fixed firm cultural beliefs the situation is more ominous than the dismal data. ${ }^{[4]}$ With the advent of new era, female education has come out of domestic confinements and has become an important role player in public health agenda. A similar study concluded that there was a significant association between female literacy and gender bias with regard to the health-seeking behavior of children, with illiterate women creating the gender divide more. Various other studies have argued the positive effect of maternal education on child health and survival. ${ }^{[5-9]}$ Female literacy should be stressed, as it plays a pivotal role in the timely seeking of health care for their children, as they are the prime caregivers. Despite their earnest intentions, many a time, mothers living in the below poverty line families and in a joint family structure, have to overcome various constraints before seeking preventive or curative healthcare services for their children. Intense awareness generation through various mass media approaches like television and radio, group meetings, and formulating culturally acceptable gender-sensitive interventions paves the way for a brighter future. ${ }^{[5-9]}$ Another concern in a developing country like India, is to ensure that gender equity prevails in the 
utilization of healthcare facilities, because if a girl child begins her formative years on a weak foundation, this continues all through her life. Gender norms and values give rise to gender inequalities, that is, differences between men and women, which systematically empower one group to the detriment of the other. ${ }^{[10]}$ There are seven types of gender inequalities - natality, mortality, special opportunity, basic facility, professional, ownership, and household. ${ }^{[4]}$ Distinction between sex (biology) and gender (the social concept) is essential to this tradition of research, as it is clear that gender inequalities in health have been in the most part socially produced rather than biologically given. ${ }^{[11]}$ In India, women are placed in a subordinate position to men, the disparity being wider in rural areas. ${ }^{[12-15]}$ Girls are neglected and discriminated against accessing preventive and curative healthcare facilities, a low girl to boy ratio (0.93) being a proof of the differential healthcare-seeking behavior between genders. ${ }^{[14,16]}$ Millenium Development Goal 3 (MDG 3) was thus formulated to ensure gender equality and women empowerment, creating equal platforms for both genders. The household being an undifferentiated unit of cooperation, inequality, and internal discrimination, proper awareness generation can pave the way for curbing this menace. ${ }^{[4]}$ However, as there is a dearth of literature on these issues, in the defined area, this study was envisaged. The objectives of the study are to find out the possible factors affecting the health-seeking behavior of mothers with regard to their children in a rural community of Darjeeling district, and the reasons for not seeking curative care for their perceived sick children.

\section{MATERIALS AND METHODS}

A community-based, cross-sectional study was carried out for three months (June to August 2011), in the Naxalbari Block of Darjeeling district, which was the rural field practice area of the Department of Community Medicine, North Bengal Medical College and Hospital. The requisite permission and ethical clearance was obtained from the Institution, Department of Community Medicine, and $\mathrm{BMOH}$ of the block. Using a multistage random sampling technique, one-third of the Gram Panchayats, then one-third of the subcenters, and subsequently one-third of the villages were selected. With the help of frontline workers like ASHAs (Accredited Social Health Activists) and ANMs (Auxiliary-Nurse-Midwives), a village-wise list of mothers (pertaining to the inclusion and exclusion criteria) was prepared. A total of 256 mothers were studied. The final sample size was calculated to be 256 after applying a design effect of two and taking non-response rate as $10 \%$. Local people of eminence and Head of the families of the area were taken into confidence and the importance of the study was duly explained to them. Mothers in the study area were also explained about the benefits of the study and their informed consent was taken. Mothers with willingness to participate in the study, who were permanent residents of the area, not severely ill and having a child with perceived sickness in the recall period were included in the study. Mothers with age of the youngest child above five years were excluded from the study. The healthcare-seeking behavior of the mother in case of the perceived illness of her child was recorded. A recall period of fifteen days was taken to avoid any recall bias. Healthcare-seeking behavior for perceived illness was recorded for only one child per mother (preferably the youngest child). The study was carried out by a house-to-house visit, with the help of peripheral health workers like ASHAs and ANMs. Data was collected using a pre-designed, pre-tested, semi-structured, open-ended, validated schedule. An in-depth interview method was carried out as and when required.

Operational definitions of literacy (any person over seven years of age who could read and write with complete understanding) and health-seeking behavior (both in preventive and curative aspects) were used. The data was then compiled and analyzed by percentages, proportions, and bivariate analysis using the Epi info version 6.0

The variables used in the study were, the working status of mother, mass media exposure of mother (like television, radio, newspaper, group meetings), educational status of mother, mothers belonging to below poverty line (BPL)/above poverty line (APL), type of family structure where mothers were residing, and gender of the child. Healthcare-seeking behaviors of the mother, both in preventive and curative aspects, along with reasons for not seeking curative care at all were also studied. The response variables were classified into two parts: (1) Preventive aspects of health care (primary immunization completed or not and if receiving other vaccines on scheduled dates) and (2) curative aspect (which was subdivided into three categories: (a) No treatment, (b) treatment from the public sector, and (c) treatment from the private sector). The first category included no treatment at all. The public sector comprised of all types of government medical institutions, community health workers, and non-governmental organization (NGO) workers; whereas, the private sector included all types of private practitioners, self-treatment, Vaidya, Hakim, homeopaths, traditional healers, and other private sector establishments.

\section{RESULTS}

Among the 256 mothers under study $(n=256)$, the age range varied from 17 to 44 years, with the mean ( \pm S.D) being $24.2 \pm 2.1$ years. One hundred and eighty-two were Hindus (71.09\%), 30 were Muslims (11.72\%), and 44 belonged to other religions $(17.19 \%)$. Mothers belonging to the general caste were159 (62.11\%) and SC/ST/OBC were $97(37.89 \%)$. Among the studied children of 256 mothers, 142 were males $(55.4 \%)$ and 114 were females $(44.5 \%)$. During the study period, the total number of children below the age of one year (infants) was 44 (17.2\%), of whom 29 were males and 15 females [Table 1]. Two hundred and twelve $(82.8 \%)$ children were aged between one and five years, with 113 males and 99 females. The results revealed that $100 \%$ of the males and females had completed their primary immunization coverage. Thus preventive healthcare-seeking behavior was practiced by all the mothers, which was a welcome finding. Regarding the curative aspect of healthcare-seeking behavior, among a total of 142 male children, no treatment was received in $16.2 \%$ of the cases ( 23 males). Treatment at the public sector was received by 97 males (in $68.3 \%$ cases) and treatment at private sector was received by 22 males (in 15.5\% cases). It indicated the promptness, concern and utmost care for male children by their mothers [Table 2]. However, the equality in seeking preventive 
healthcare services, like immunization coverage, among mothers for their children of both genders, was not reflected in the case of curative healthcare-seeking behavior. Among the studied 114 female children, strikingly no treatment was received in $42.1 \%$ of the cases. Treatment at public sector was received by 51 females (in $44.7 \%$ cases) and treatment at private sector was received by 15 females (in $7.5 \%$ cases) [Table 2]. The findings of the Chi square test revealed the following findings [Table 3]. Mass media exposure was categorized as not exposed and exposed. Of the 27 mothers (10.5\%) not exposed, healthcare behavior was sought by only eight mothers (29.6\%) and among 229 mothers $(89.5 \%)$ exposed to mass media, 158 mothers $(69 \%)$ sought health care. The association was found to be statistically significant. $\left(P<0.05, \mathrm{df}=1, \chi^{2}=16.42\right)$. The working status of the mother was categorized as non-working and working mothers. Among 178 (69.5\%) non-working mothers, 98 (55.1\%) had health-seeking behavior. Among the working mothers, 55.1\% had healthcare-seeking behavior. No statistically significant association was found $\left(P>0.05, \mathrm{df}=1, \chi^{2}=0.00\right)$. Educational status of the mother was categorized as literate and illiterate mothers. Of 62 illiterate mothers, $24.2 \%$ had healthcare-seeking behavior, whereas, among 194 (75.78\%) literate mothers, healthcare-seeking behavior was present in $78.3 \%$ of the cases. The association was found to be statistically significant $\left(P<0.05, \mathrm{df}=1, \chi^{2}=60.76\right)$.

The mothers were again categorized as Below Poverty Line (BPL) card holders and non-holders. Among 194 (75.78\%) BPL card holder mothers, 151 (77.8\%) displayed health-seeking behavior, whereas, among 62 non-BPL mothers (24.2\% cases), $16(25.8 \%)$ sought healthcare services. A statistically significant

\begin{tabular}{|c|c|c|c|}
\hline Sex of child & $\begin{array}{c}\text { Less than } \\
\text { one year }\end{array}$ & $\begin{array}{c}\text { Greater than } \\
\text { one year }\end{array}$ & Total \\
\hline Male children & 29 & 113 & $142(55.4)$ \\
\hline Female children & 15 & 99 & $114(44.5)$ \\
\hline Total & 44 & 212 & $256(100)$ \\
\hline
\end{tabular}

Figures in parentheses indicate percentage association was noted. $\left(P<0.05, \mathrm{df}=1, \chi^{2}=56.08\right)$. Among 177 mothers (69.14\%) living in joint families, $24.8 \%$ had healthcare-seeking behavior, whereas, among 79 mothers $(30.85 \%)$ living in nuclear families, $67.08 \%$ mothers sought health care. The association was found to be statistically significant $(P<0.05$, $\left.\mathrm{df}=1, \chi^{2}=41.39\right)$. The association between the healthcare-seeking behavior of the mothers and gender of their child was found to be statistically significant. Among 142 mothers having a male child, 83.8\% sought healthcare services, whereas, among 114 mothers having a female child, $57.9 \%$ mothers sought health care $\left(P<0.05, \mathrm{df}=1, \chi^{2}=21.18\right)$. Unfortunately, out of the studied 256 mothers, with each having a perceived sick child, health care behavior was not sought in $27.7 \%$ of the cases. Among 142 male and 114 female children, no treatment was received in $16.2 \%$ of the cases and $42.1 \%$ of the cases, respectively. The reasons stated by their mothers for not seeking health care behavior were noted. Multiple responses were given; $71.2 \%$ of the mothers opined that ignorance, lack of awareness, fixed firm cultural beliefs, male-dominated society, more concern for the well-being of the male child, as he was the future bread winner of the family, and the final word of the head of the family, were contributory factors; $62.3 \%$ of the mothers stated the cause to be dissatisfaction with the health care services, along with lack of accountability and humaneness of the healthcare providers. Lack of accessibility, availability, and affordability of the health care services provided was also a cause, according to $57.11 \%$ of the mothers. According

\begin{tabular}{|c|c|c|c|}
\hline $\begin{array}{l}\text { Curative } \\
\text { health seeking } \\
\text { behavior }\end{array}$ & $\begin{array}{c}\text { Perceived } \\
\text { sick males } \\
(n=142)\end{array}$ & $\begin{array}{c}\text { Perceived } \\
\text { sick females } \\
(n=114)\end{array}$ & $\begin{array}{l}\text { Total perceived } \\
\text { sick children } \\
(n=256)\end{array}$ \\
\hline No treatment & $23(16.2)$ & $48(42.1)$ & $71(27.7)$ \\
\hline $\begin{array}{l}\text { Treatment at } \\
\text { public sector }\end{array}$ & 97 (68.3) & $51(44.7)$ & $148(57.8)$ \\
\hline $\begin{array}{l}\text { Treatment at } \\
\text { private sector }\end{array}$ & $22(15.5)$ & $15(13.2)$ & $37(14.5)$ \\
\hline
\end{tabular}

Figures in parentheses indicate percentage

\begin{tabular}{|c|c|c|c|c|c|}
\hline \multirow[t]{2}{*}{ Factors } & \multirow[t]{2}{*}{ Category } & \multicolumn{2}{|c|}{$\begin{array}{l}\text { Health-seeking } \\
\text { behavior }\end{array}$} & \multirow[t]{2}{*}{$\chi^{2}$ value, $P$ value, df } & \multirow[t]{2}{*}{ Odds ratio $(95 \% \mathrm{Cl})$} \\
\hline & & Yes & No & & \\
\hline \multirow[t]{2}{*}{ Mass media exposure } & Present & $158(69)$ & $71(31)$ & \multirow{2}{*}{$\begin{array}{l}16.42,0.00,1 \\
\text { (association significant) }\end{array}$} & \multirow{2}{*}{$\begin{array}{c}\mathrm{OR}=5.29 \\
(2.07-13.88)\end{array}$} \\
\hline & Absent & $08(29.6)$ & $19(70.3)$ & & \\
\hline \multirow[t]{2}{*}{ Working status of mothers } & Not working & $98(55.1)$ & $80(44.9)$ & \multirow{2}{*}{$\begin{array}{l}0.0,0.99,1 \\
\text { (not significant) }\end{array}$} & \multirow[t]{2}{*}{$\mathrm{OR}=1(0.56-1.76)$} \\
\hline & Working & $43(55.1)$ & $35(44.8)$ & & \\
\hline \multirow[t]{2}{*}{ Educational status } & Illiterate & $15(24.2)$ & $47(75.8)$ & \multirow{2}{*}{$\begin{array}{l}60.76,0.00,1 \\
\text { (association significant) }\end{array}$} & \multirow{2}{*}{$\begin{array}{c}\mathrm{OR}=11.34 \\
(5.5-23.62)\end{array}$} \\
\hline & Literate & $152(78.3)$ & $42(21.6)$ & & \\
\hline \multirow[t]{2}{*}{ Type of family structure } & Joint family & $44(24.8)$ & $133(75.1)$ & \multirow{2}{*}{$\begin{array}{l}41.39,0.00,1 \\
\text { (association significant) }\end{array}$} & \multirow[t]{2}{*}{$\mathrm{OR}=0.16(0.09-0.30)$} \\
\hline & Nuclear family & $53(67.1)$ & $26(32.9)$ & & \\
\hline \multirow[t]{2}{*}{ Mothers having BPL Card } & Yes & $151(77.8)$ & $43(22.2)$ & \multirow{2}{*}{$\begin{array}{l}56.08,0.00,1 \\
\text { (association significant) }\end{array}$} & \multirow{2}{*}{$\begin{array}{l}\mathrm{OR}=10.10 \\
(4.9-20.73)\end{array}$} \\
\hline & No & $16(25.8)$ & $46(74.2)$ & & \\
\hline \multirow[t]{2}{*}{ Mothers according to gender of their child } & Male & $119(83.8)$ & $23(16.2)$ & \multirow{2}{*}{$\begin{array}{l}21.18,0.00,1 \\
\text { (association significant) }\end{array}$} & \multirow[t]{2}{*}{$\mathrm{OR}=3.76(2.03-7.02)$} \\
\hline & Female & 66 (57.9) & $48(42.1)$ & & \\
\hline
\end{tabular}

Figures in parentheses indicate percentage 
to $36 \%$ of the mothers, inconvenience of transport facilities, religious misinterpretations, socioeconomic constraints, and women's restricted movements played a role.

\section{DISCUSSION}

The multidimensional growth of a nation is primarily dependent on its health, manpower, andeffective service utilization, and extends beyond the narrow limits of curative care, encompassing the preventive and promotive aspects as well. ${ }^{[17]}$ For effective health outcomes, it is mandatory that women utilize the services at par with men, more so because they are the prime caregivers to the children in the community. Starting from immunization coverage to accessing curative health care, health-seeking behavior largely displays the needs felt and awareness generated in the individual as well as the community. The existing literature on care-seeking in India, quantitatively displays the female disadvantage in healthcare use-rates. ${ }^{[18]}$ However, there is a lack of quantitative data on the potential gender disparities existing in household recognition of illness, type of care used, and monetary expenditure for the health services, making it difficult for policy makers to formulate gender-sensitive interventions. ${ }^{[18,19]}$ Community-based studies have also found a significant gender differential of healthcare use in rural India. They have found that the proportion of sick female and male newborn infants receiving any treatment is 28.8 and $63.1 \%$, respectively. ${ }^{[18]}$ Similarly, in the Matlab area in Bangladesh, girls are less likely to get even free treatment than boys. ${ }^{[20]}$ Gordon and Wyon have found in the Khanna study in Punjab that girls received less and worse medical care than boys, in the under three age group. ${ }^{[16]}$ Cross-sectional surveys of practitioners and care providers have reported discriminatory care-seeking for boys and girls in India and Bangladesh. ${ }^{[21,22]}$ Regional and gender differences in the health-seeking behavior among the migrants from Tamil Nadu and Uttar Pradesh in Delhi are observed. ${ }^{[23]}$ The maternal education and living standard of the household have positive effects on the Oral Rehydration Treatment rate for boys, but not for girls, especially in the central and eastern regions of India. ${ }^{24]}$ The NFHS-1 study of 1992-1993, shows that mother's education continues to be a powerful, positive and significant predictor of utilization of child healthcare services in India, after controlling a number of other demographic, socioeconomic, and spatial variables. ${ }^{[25]}$ Prevalence of visits to the medical facilities is highest among children aged six to twenty-three months, children of lower birth orders, children in urban areas, children of mothers with at least secondary education, and children of mothers exposed to any sort of mass media. ${ }^{[19]}$ Additionally, factors related to the place of residence, socioeconomic status, cost, quality, and location of health services may account for variations in the use of maternal health care. Women's age, ethnicity, education, religion, culture, clinical need for care, and decision-making power interact in different ways to determine the health-seeking behavior. ${ }^{[26,27]}$ Another study showed, that mothers often did not perceive neonatal illnesses serious enough for the use of a healthcare provider. ${ }^{[19]}$ However, for effective and favorable health outcomes a responsible, productive, and competent health workforce is an essential prerequisite. ${ }^{[28]}$ Sadly, rural health bears the maximal brunt. The prevalence of Infant Mortality Rate is two and a half times more, prevalence of malaria is three times more, and malnourishment among the reproductive age group females is three times more in the rural population than in the urban population. ${ }^{[29]}$ However, illiteracy, ignorance, lack of awareness of the necessity of services provided, customs, beliefs, deep rooted faith in traditional healers and TBAs, lack of accountability of health care providers, lack of credibility of public health facilities, concern over cost of medicine, reputation of healthcare provider, and access to a healthcare provider (covering geographical, socioeconomic, and gender distances) act as hindrances in the effective service utilization by the beneficiaries. ${ }^{[30-32]}$ Recall bias may also lead to inaccurate or underestimation of the care-seeking behavior, for newborns. However, as Sudman and Bradburn have found, it is likely to be minimized through a face-to-face questionnaire format, which aided memories of the respondents. Another bias is the misclassification bias, which occurs because mothers may misrepresent the actual to create a more socially-desirable impression. ${ }^{[33]}$

\section{CONCLUSION}

The present study found that among the 256 mothers studied the majority were Hindus, belonged to the general caste and were in the age range of 24.2 years with an SD of 2.1 years. One hundred and forty-two mothers had a male child and 114 mothers had a female child. One hundred percent of the children, irrespective of gender, had completed their primary immunization. Regarding curative healthcare-seeking behavior, $16.2 \%$ males and $42.1 \%$ females received no treatment. Factors like mass media exposure of mothers, literacy status of mothers, below poverty line card holder mothers, and those residing in joint family structures were found to be significantly associated with the healthcare-seeking behavior of the mothers. Association between healthcare-seeking behavior of mothers and gender of their child was also found to be statistically significant. A majority of the mothers opined that ignorance, lack of awareness, fixed firm cultural beliefs, male-dominated society, more concern for the well-being of the male child (he being the future torch bearer of the family), and the final word of the head of the family, compounded with the lack of accountability of the health workers, were a few factors for their not seeking curative health care services. These findings may have implications in future, with health planners and policy makers formulating more gender-sensitive and culturally appropriate health interventions for promotion of healthcare-seeking behavior in rural India - seeking behavior irrespective of gender differences.

\section{RECOMMENDATIONS}

Intense awareness generation through a mass media approach, stressing on female literacy, improving the overall socioeconomic conditions through various income generation schemes, along with counseling the local people of eminence and head of the families on the benefits of timely and appropriate healthcare-seeking behaviors, both in preventive and curative aspects, may lead to the desired health outcomes and favorable health indicators. Increasing the motivation and accountability of the frontline health-workers and addressing the dissatisfaction of the beneficiaries may lead to effective service utilization and favorable health indicators. Percolating the message 
of gender equality deep into the community seems to be the need of the hour.

\section{LIMITATIONS}

Taking a larger sample size could detect significant differences in certain outcomes. The definitiveness of the study results were limited by subjective measurements of certain outcomes, like perceived severity of childhood illness. This study had a scope of recall bias and misclassification bias, as well as missing out on those mothers who were at their parental homes during the study period. Affordability, accessibility, availability, and occupation of the head of the family, which could have influenced the outcomes, could not be taken into consideration.

\section{ACKNOWLEDGMENT}

We are thankful to Dr. Dipta Kanti Mukhopadhyay, Assistant Professor, Bankura Sammilani Medical College, West Bengal, for his help and support

\section{REFERENCES}

1. Uzma A, Underwood P, Atkinson D, Thackrah R. Postpartum health in a Dhaka slum. Soc Sci Med 1999;48:313-20.

2. Rahman SA. Utilization of Primary Health Care Services in Rural Bangladesh: The population and provider perspectives. Unpublished PhD Thesis, London School of Hygiene and Tropical Medicine, University of London; 2000.

3. Ahmed S, Adams A, Chowdhury M, Bhuiya A. Gender, socio-economic development and health-seeking behaviour in Bangladesh. Soc Sci Med 2000;51:361-71.

4. Sen A. Many faces of gender inequality. Frontline 2001. p. 18 (22). Available from: http://www.hindu.com/fline/fl1822/18220040.htm. [Last accessed on 2011 Dec 31].

5. Caldwell J, Caldwell P. Women's position and child mortality and morbidity in LDC's. Research Paper. Canberra: Department of Demography, Research School of Social Sciences, Australian National University; 1988.

6. Cleland J. Maternal education and child survival: Further evidence and explanations. In: Cladwell J, editor. What we know about health transition: The cultural, social, and behavioural determinants of health. Canberra: Australian National University; 1990. p. 400-19.

7. Barrera A. The role of maternal schooling and its interaction with public health programs in child health production. J Dev Economics 1990;32:69-91.

8. Dreze J. A surprising exception: Himachal's success in promoting female education. Manushi: A Journal about Indian women and Society 1999. p. 112.

9. Dreze J, Murthi M. Fertility, education and development: Evidence from India. Population Dev Rev 2001;27:33-64.

10. WHO document 2011. Why gender and health? Available from: http:// www.who.int/gender/genderandhealth/en/index.html. [Last accessed on 2011 Jul 8].

11. Annandale E, Hunt K. Gender inequalities in health: Research at crossroads. In: Annandale E, Hunt K, editors. Gender inequalities in health. $1^{\text {st }}$ ed. Philadelphia: Open University Press; 2000. p. 1-35.

12. Fikree FF, Pasha O. Role of gender in health disparity: The South Asia context. BMJ 2004;328:823-6.

13. Sharma DC. Widespread concern over India's missing girls.
Selective abortion and female infanticide cause girl-to-boy ratios to plummet. Lancet 2003;362:1553.

14. Borooah VK. Gender bias among children in India in their diet and immunisation against disease. Soc Sci Med 2004;58:1719-31.

15. Nielsen BB, Liljestrand J, Hedegaard M, Thilsted SH, Joseph A. Reproductive pattern, perinatal mortality, and sex preference in rural Tamil Nadu, South India: Community based, cross sectional study. BMJ 1997;314:1521-4.

16. Registrar General of India. Census of India. New Delhi: Registrar General of India; 2001. Population tables. Available from: http://www.censusindia. gov.in. [Last accessed on 2011 Nov].

17. Park K. PARK'S Textbook of Preventive and Social Medicine. $20^{\text {th }}$ ed. Prem Nagar, Jabalpur: M/s Banarsidas Bhanot Publishers; 2009. p. 791-3.

18. Walia I, Kumar V. Utilization of neonatal health care in a community. Indian Pediatr 1984;21:925-31.

19. National Neonatalogy Forum. Save the Children. The state of India's newborns. Washington, DC National Neonatology Forum; 2004. Available from: http://www.savethechildren.org/publications/india_pdf/SOIN_ Document.pdf.pdf. [Last accessed on 2011 Nov 20].

20. Chen L, Huq E, D'Souza S. Sex bias in the family: Allocation of food and health care in rural Bangladesh. Population Dev Rev 1981;7:54-70.

21. Ganatra B, Hirve S. Male bias in health care utilization for under fives in a rural community in western India. Bull World Health Organ 1994;72:101-4.

22. Hossain MM, Glass RI. Parental son preference in seeking medical care for children less than five years of age in a rural community in Bangladesh. Am J Public Health 1988;78:1349-50.

23. Basu AM. Is discrimination in food really necessary for explaining sex differentials in childhood mortality? Population Stud 1989;43:193-210.

24. Rao KV, Mishra VK, Retherford RD. Knowledge and use of Oral Rehydration Therapy for childhood diarrhoea in India: Effects of exposure to mass media. NFHS Subject Report No.10. IIPS, India and East-West Centre, Program on Population, Honolulu, USA10: 1998.

25. Govindaswamy P, Ramesh BM. Maternal education and the utilization of maternal and child health services in India. National family Health survey Subject Report, No.5, Mumbai International Institute for Population Sciences: And Calvertor, Maryland: Macro International Inc.; 1997.

26. Government of India. National Family Health Survey (NFHS) III (2005-06), India Report Bombay: International Institute for Population Sciences; 2007.

27. Haas J. The cost of being a woman. N Engl J Med 1998;338: 1694-5.

28. WHO. Not Enough Here... Too Many There... Health Workforce in India. World Health Organization. Country Office for India 2007. p. 1. Available from: http://www.whoindia.org/LinkFiles/Human Resources Health Workforce in India, Apr07.pdf [Last accessed on 2011 Aug 23].

29. Park K. PARK'S Textbook of Preventive and Social Medicine. $20^{\text {th }}$ ed. Prem nagar, Jabalpur: M/s Banarsidas Bhanot Publishers; 2009. p. 802-12.

30. Rural healthcare system in India. Available from: http://www.mohfw.nic.in/ rural health care system in India.pdf. [Last accessed on 2011 Jul 10].

31. Community health workers: What do we know about them? WHO publication 2007. Available from: http://www.who.int/hrh/documents/ community_health_workers_brief.pdf. [Last accessed on 2011 Jun 30].

32. WHO. Primary health care. WHO Document 2011. Available from: http:// www.who.int/topics/primaryhealthcare/en. [Last accessed on 2011 Aug 22].

33. Sudman S, Bradburn NM. Effects of time and memory factors on response in surveys. J Am Statist Assoc 1973;68:805-15.

How to cite this article: Ghosh N, Chakrabarti I, Chakraborty M, Biswas R. Factors affecting the healthcare-seeking behavior of mothers regarding their children in a rural community of Darjeeling district, West Bengal. Int J Med Public Health 2013;3:12-6.

Source of Support: Nil, Conflict of Interest: None declared. 